\title{
Knee Joint Radiographic Examination Technique with Anteroposterior and Lateral Projections in Osteoarthritis Cases
}

\author{
Rofiqoh Evi Prastiwi', Bagus Aji Pangestu², Fani Susanto ${ }^{3}$ \\ ${ }^{1,2,3}$ Radiologic Imaging Technology, Universitas Muhammadiyah Purwokerto, Indonesia
}

\begin{tabular}{l} 
ARTICLE INFO \\
\hline Article history: \\
DOI: \\
10.30595/pshms.v2i.222 \\
Submitted: \\
December 6, 2021 \\
Accepted: \\
January 21, 2022 \\
Published: \\
January 26, 2022
\end{tabular}

Keywords:

Radiography; osteoarthritis; knee joint; anteroposterior; lateral

\begin{abstract}
Radiographic examination of the knee joint in Osteoarthritis (OA) cases was generally performed using anteroposterior (AP), lateral and oblique projections. However, at the Regional General Hospital (RSUD) of Ajibarang, in the case of OA the knee joint only used AP and lateral projections. The purpose of this study was to determine the radiographic examination procedure and ensure the criteria for the image generated from the AP projection and lateral examination of the knee joint in OA cases. This research was a qualitative descriptive with a case study approach. Collecting data on 1 knee joint patient with OA in Ajibarang Hospital using observation, documentation and interviews with radiographers and radiologist. Data analysis used open coding in the form of quotations. The results showed that the AP and lateral projections were performed with the central ray perpendicular to the cassette and showed the distal femur, tibia, proximal fibula and patella, the femoropatellar joint and the knee joint were exposed and the true lateral was shown by superposition of the femoral condyles. Finally, examination of the knee joint of OA cases at Ajibarang Hospital with $\mathrm{AP}$ and lateral projections can still display the anatomy of interest and determine the diagnosis of OA cases.
\end{abstract}

This work is licensed under a Creative Commons Attribution 4.0 International License.

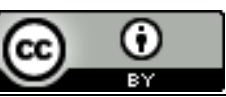

Corresponding Author:

Rofiqoh Evi Prastiwi,

Radiologic Imaging Technology, Universitas Muhammadiyah Purwokerto, Indonesia

Email: rofiqoheviprastiwi@gmail.com

\section{INTRODUCTION}

The development of radiology began with the discovery of x-rays by Wilhelm Conrad Rontgen, a German physicist through his experiments on November 8, 1895 has provided a development for science and technology including into the world of medicine. The principle of radiodiagnostics is that x-rays that hit an object will produce a radiograph image that can help establish the diagnosis of a disease, so the technique of examination of an organ becomes more varied with the support of various specifications of more modern diagnostic aircraft. One such examination is an examination of the knee joint organ.

Knee joint is one of the joints that have a complex function (Smith, el al., 2010). Genu or Kene Joit is the largest joint and the most complex motion joint in the human body arranged by a combination of 2 conslus, the femur and the supice of the tibia. The slit of the genu joint consists of lateral cartilage of the menikus and the medial of the "C" shaped menikus associated with the transverse ligament. Menikus will dampen the ups and downs of the knee by shaking the knee. [1]

Radiographic examination in knee joint cases is the most common extremity examination experienced by elderly patients. Most of the patients present with knee pain, making it difficult for the radiographer to position the knee joint radiography. Proper positioning will result in the correct diagnosis by the radiologist, therefore it is important for the radiographer to understand the procedure for radiographic examination of the knee joint in cases of osteoarthritis correctly. In examination of the knee at the Radiology 
Installation of Ajibarang Hospital using $\mathrm{AP}$ and lateral projections with a vertical beam direction perpendicular. While the standard examination of the direction of the beam at the knee joint with a lateral projection at an angle.

\section{RESEARCH METHOD}

This type of analysis uses qualitative with a case study approach of shoulder joint dislocation. This data collection is located at the installation of Ajibarang Hospital. The subjects used were related to the examination of knee joint radiography. Subjects are described based on gender and the examination techniques used are ap and lateral.

\section{RESULT AND DISCUSSIONS}

3.1. Result

A patient on behalf of Mr. S, 56 years old on December 14, 2020 with clinical osteoarthritis of the knee joint, a radiographic examination of the knee joint was performed with Anteroposterior (AP) and Lateral projections. The patient's condition is cooperative and can walk normally with complaints of knee.

Table 1. Preparation Tools and Materials

\begin{tabular}{ccc}
\hline Tools Name & Model & Serial number \\
\hline $\begin{array}{c}\text { 1. X-ray } \\
\text { aircraft }\end{array}$ & SIEMENS OPTI 135/30/55 R & 524503 \\
$\begin{array}{c}\text { 2. Image } \\
\text { Receiver }\end{array}$ & Digital Image Receptor & U6- \\
3. & Digital Radiography Printer & T259B249NT02Processing \\
Processing Film & CARESTREAM / 5950 LASER IMAGER & - \\
\hline
\end{tabular}

The patient comes to the radiology installation with a request letter for a radiology examination. The letter is then registered at the radiology registration section. After registration on the hospital information and management system (SIM-RS), the officer handed it over to the radiographer. The radiographer prepares the equipment used in the radiographic examination of the knee joint, then inputs patient data on digital radiography. After everything is ready, the radiographer calls the patient into the room. In the patient's room, it is explained about the examination procedure to be carried out (anamnesis). During the radiographic examination, the delivery person or the patient's family is prohibited from accompanying him in the room for radiation safety for the patient's family. Furthermore, the examination is carried out with two projections, namely AP and Lateral. There is no special preparation, the patient is only asked to remove metal objects that can cause artifacts and fold the pants up so that the genu can be seen clearly and the patient is given directions or explanations regarding the examination to be carried out.

Table 2. Knee joint radiography examination protocol in cases of osteoarthritis at Ajibarang Regional General Hospital

\begin{tabular}{ll}
\multicolumn{1}{c}{ Indicator } & \multicolumn{1}{c}{ Description } \\
\hline a. Patient Position & Antero Posterior (AP) : \\
& The patient is positioned in a supine sleeping position on the \\
& examination table without rotation from the pelvis \\
& - Provide pads for the patient's head \\
& - The lower leg should be full extension \\
& Lateral : \\
& - Position the patient laterally recumbent \\
& - Provide pads for the patient's head \\
& - Provide support (jams) for the knee to be placed behind the knee \\
& being examined to prevent over-rotation \\
& Antero Posterior (AP) : \\
& - Align and middle legs and knees to the CR and to the centerline of \\
& the table or IR \\
& - Turn the foot to medial $3^{\circ}$ to $5^{\circ}$ for the knee true \\
& - Place sandbags on the feet and ankle joints to stabilize if needed \\
& Lateral : \\
& - The body and legs are regulated rotation, so that the knee joint is in a \\
& true lateral position
\end{tabular}

Proceeding homepage: https://conferenceproceedings.ump.ac.id/index.php/pshms/issue/view/10 
- Slear the knee joint $20^{\circ}$ to $30^{\circ}$

- Align the legs and knees in the middle of the cassette

c. Central Ray \& Antero Posterior (AP) :

Central Point - Direct parallel rays parallel to the articular faset (tyrial plateau) For patients of average size, CR is perpendicular to IR (see Note).

- Point the vertical CR perpendicular to the cassette to a point 12 inches $(1.25 \mathrm{~cm})$ below the patella muster

Lateral :

- Point 50 to 70 rays towards the chepalad. Aim point to 1 inch $(2.5 \mathrm{~cm})$ distal from epicondilus medialis

d. Focus Film Antero Posterior (AP) \& Lateral : $100 \mathrm{~cm}$

Distance (FFD)

f. Exposure Factor $\quad$ Antero Posterior (AP) \& Lateral : $\mathrm{kV}=75, \mathrm{mAs}=8$

Figure 1. ap projection radiograph - knee joint Mr. S, 56 years old on December 14, 2020 with clinical osteoarthritis of the knee joint, a radiographic examination of the knee joint was performed with Anteroposterior (AP)

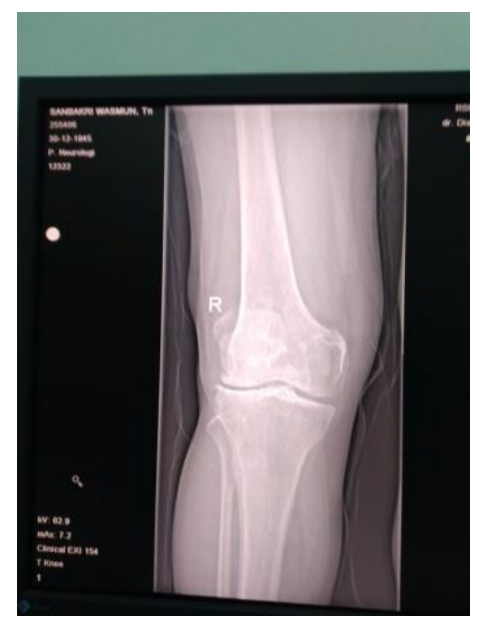

Radiograph criteria of Antero Posterior (AP) Knee joint: 1). Distal Femur and proximal tibia and fibula are clearly visible; 2). Femorotibial joint slits appear to open, with the articular phase of the tibia visible at the ends only minimally visualized surface area (Figure 1.6); 3). There is no rotation as evidenced by symmetry: femur, femoral conslusal appearance and tibialis se joint space

Figure 2. Lateral radiograph - knee joint Mr. S, 56 years old on December 14, 2020 with clinical osteoarthritis of the knee joint, a radiographic examination of the knee joint was performed with Lateral

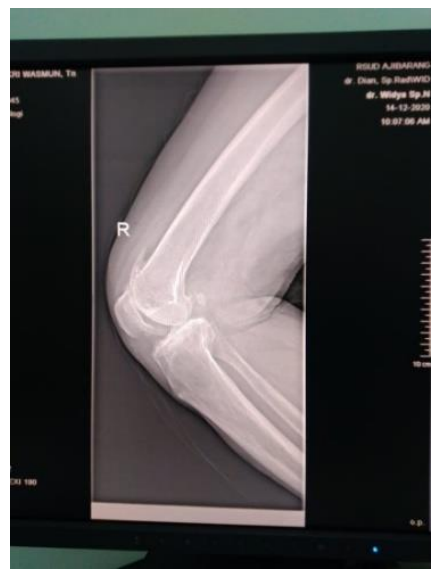


Radiograph criteria of Lateral Knee joint: 1) Distal femur, proximal tibia and fibula and patella are clearly; 2) visible in radiograph image; Femoropatellar joint and knee joint seen opening; True lateral indicated by femoral condyles superposition.

Film Processing: Film processing conducted at the Radiology Installation of Ajibarang Hospital using Digital Radiography. Results of Examination and reading of Radiology doctor Knee joint examination with cases of osteoarthritis genu dextra is made with AP projections: Effects of the projections; Osteoarthritis genu dextra (grade 3); Good bone structure.

\subsection{Discussion}

The results of observations on knee joint examination at Ajibarang Hospital there is a difference between the theory in Bontranger's book ninth edition with the one in the field for the theory of projection knee ap dn lateral using supine but when done in the field, from the position of routine patients in the hospital using erect, supine with cases of OA knee joint when the patient's condition is really not strong to stand, When lateral knee joint projection is done in the hospital there is no breastfeeding as in bontrager theory, but the use of perpendicular light and not doing counseling can still describe anatomy and diagnose osteoarthrits abnormalities in knee join. Osteoarthritis genu dextra (grade 3), good bone structure. So it can be concluded that the use of lateral knee joint projection with perpendicular light can still describe anatomy and confirm the diagnosis of cases of Osteoarthritih knee joint.

\section{CONCLUSION}

From some of the descriptions described above, it can be concluded that the knee joint examination technique with cases of Osteoarthritis at the Radiology Installation of Ajibarang Hospital, was carried out with Antero Posterior (AP) and lateral projections. The use of perpendicular rays in the lateral projection of the knee joint can still describe the overall anatomy and can confirm the doctor's diagnosis in the case of Osteoarthritis of the knee joint.

\section{Acknowledgements}

Acknowledgments are given to the Clinical Instructure and radiographer at the Radiology Installation at the Regional General Hospital (RSUD) of Ajibarang, who has helped in this research and the supervising lecturer of Imaging Radiology Technology D4 UMP who helped in completing this research.

\section{REFERENCES}

[1] Saladin, S. Kenneth, "Anatomy \& Physiology: The Unity Of Form And Function. Eighteen Edition," New York: McGraw-Hill Education, 2015.

[2] Hiswara, Eri, "Buku Pintar Proteksi dan Kesalamatan Radiasi di Rumah Sakit," Batan Press: Jakarta Selatan, 2015.

[3] Bontrager, John Lampignano, Leslie Kendrick, "Textbook of Radiographic Positioning and Related Anatomy,"Mosby Elsevier, 2018 